\title{
CLÍNICA E TRATAMENTO DAS INFECÇÕES PELOS VÍRUS Herpes Símplex TIPO 1 E 2
}

\author{
CLINICAL MANIFESTATIONS AND TREATMENT OF INFECTIONS \\ CAUSED BY Herpes Simplex 1 AND 2 VIRUSES
}

Benedito Antônio Lopes da Fonseca

Docente do Departamento de Clínica Médica do Hospital das Clínicas da Faculdade de Medicina de Ribeirão Preto da Universidade de São Paulo.

Correspondência: Prof.Dr. Benedito Antônio Lopes da Fonseca - Departamento de Clínica Médica da Faculdade de Medicina de Ribeirão Preto da Universidade de São Paulo - Av. Bandeirantes, 3900 - CEP: 14048-900 - Ribeirão Preto - SP. Fax: 55 (016) 6336695.

FONSECA BAL. Clínica e tratamento das infecções pelos vírus herpes simplex tipo 1 e 2 . Medicina, Ribeirão Preto, 32: 147-153, abr./jun. 1999.

RESUMO: As infecções pelos vírus herpes símplex são conhecidas da raça humana desde a antiguidade. Estes vírus são responsáveis por uma gama de infecções que vão desde erupções cutâneas até quadros graves de encefalite. Atualmente, um antiviral específico para estes vírus, o aciclovir, está disponível para o tratamento destas infecções. Nesta revisão, o uso do aciclovir é discutido em relação às diversas manifestações da infecção herpética.

UNITERMOS: HerpesVírus 1 Humano. HerpesVirus 2 Humano. Aciclovir.

\section{INTRODUÇÃO}

Infecções, em seres humanos, pelos vírus herpes símplex (HSV) foram inicialmente documentadas na Grécia Antiga. Hipócrates usou a palavra "herpes", cujo significado, em grego, é rastejar ou engatinhar, para descrever lesões que apareciam umas próximas às outras. Embora a natureza vesicular das lesões associadas com infecções herpéticas tenha sido bem caracterizada previamente, só em 1893, Vidal reconheceu a transmissão interpessoal das infecções herpéticas $^{(1,2)}$.

Após a infecção primária, anticorpos neutralizantes para HSV são detectados no soro de indivíduos infectados. Subseqüentemente, alguns indivíduos soropositivos desenvolvem lesões labiais ou genitais recorrentes, expressando clinicamente a propriedade biológica própria dos HSV, isto é, a capacidade de recorrer periodicamente, na presença de imunidade humoral (reativação da infecção latente). $\mathrm{O}$ espectro de doenças causadas pelos HSV inclui in- fecções primárias e recorrentes de membranas mucosas (por exemplo, gengivoestomatite, herpes labial e genital), ceratoconjuntivite, infecção neonatal, encefalite e infecções viscerais em indivíduos imunocomprometidos (por exemplo, esofagite). Um aspecto importante, na discussão das infecções pelos HSV, é a distinção entre dois tipos virais, o HSV-1 e o HSV-2. O HSV-1 tem sido associado mais freqüentemente a infecções não-genitais, enquanto que o HSV-2 tem sido associado com doença genital. Atualmente, considera-se que esta relação não seja estanque, visto que uma pequena porcentagem das infecções genitais são devidas ao HSV-1 e o mesmo é verdade para a interrelação entre o HSV-2 e as infecções não-genitais.

$\mathrm{O}$ virion dos HSV possui quatro componentes: 1) um cerne eletrodenso que contém o DNA viral; 2) um capsídeo icosaédrico; 3) uma substância amorfa, denominada tegumento, representando o acúmulo de proteínas, que envolve o capsídeo e 4) um envelope lipoprotéico. Para iniciar infecção, os HSV precisam ligar-se aos receptores celulares, fundir seu envelope 
com a membrana plasmática, e permitir que o capsídeo, recentemente desenvelopado, seja transportado até os poros nucleares. O DNA é liberado no núcleo e a replicação dá-se por eventos que incluem transcrição, síntese de DNA, montagem do capsídeo, empacotamento do DNA e aquisição do envelope.

Este artigo não discutirá a replicação viral e sua importância na fisiopatologia das doenças causadas por estes vírus, bem como se absterá da discussão da epidemiologia e diagnóstico destas afecções. O enfoque deste artigo será a revisão das manifestações clínicas, resultantes das infecções por estes vírus e o arsenal terapêutico disponível.

\section{MANIFESTAÇÕES CLIINICAS DAS INFEC- ÇÕES PELOS HSV}

\section{Infecção Mucocutânea}

Existe uma grande variabilidade na sintomatologia clínica das infecções primárias pelo HSV-1; infecção assintomática é a regra ${ }^{(3)}$. O período de incubação varia de dois (2) a doze (12) dias, levando, em média, quatro (4) dias. Infecção primária pelo HSV-1 resulta em excreção oral de vírus por até vinte e três (23) dias (média: sete a dez (7-10) dias). Anticorpos neutralizantes aparecem entre o quarto $\left(4^{\circ}\right)$ e o sétimo $\left(7^{\circ}\right)$ dia após o início da doença, e os níveis mais elevados são observados em aproximadamente três (03) semanas. A doença sintomática, em crianças, é caracterizada pelo envolvimento da mucosa bucal e gengival. A duração da enfermidade é de duas a três (2-3) semanas e a temperatura pode chegar a $40^{\circ} \mathrm{C}$. Crianças com infecção primária sintomática apresentam, freqüentemente, impossibilidade de deglutir líquidos por causa da dor associada. Lesões dentro da boca apresentam-se, inicialmente, como vesículas e evoluem para ulcerações rasas sobre uma base eritematosa. Linfoadenopatia submandibular é comum em pacientes com gengivoestomatite primária, mas, rara nas infecções recorrentes. Outros achados incluem dor de garganta, mal-estar, linfoadenopatia cervical dolorosa, e, como exposto anteriormente, dificuldade para deglutir.

Uma distinção clínica deve ser feita entre lesões gengivais intra-orais, indicativas de infecção primária, e lesões labiais, indicativas de infecções recorrentes. Faringite é comum, aparecendo juntamente com uma síndrome "mononucleose-like", principalmente naqueles pacientes que desenvolvem infecções primárias na adolescência ou idade adulta. $\mathrm{O}$ diagnóstico diferencial da gengivoestomatite pelo
HSV inclui a herpangina (normalmente causada pelos “coxsackievirus"), candidíase oral, mononucleose pelo vírus Epstein-Barr, lesões induzidas por quimioterapia ou radioterapia, e síndrome de Stevens-Johnson.

O início das lesões orolabiais recorrentes é anunciado por um pródromo de dor, queimação, formigamento, ou prurido, o qual, geralmente, dura aproximadamente seis (06) horas e é seguido pelo aparecimento das vesículas ${ }^{(4)}$. Vesículas aparecem, comumente, na borda labial e persistem, em média, por quarenta e oito (48) horas. As vesículas são, geralmente, em número de três a cinco. Lesões progridem para pústulas, úlceras e crostas em um período de setenta e duas a noventa e seis (72-96) horas e curam, por completo, dentro de oito a dez (8-10) dias. A dor é mais importante no início mas cessa em noventa e seis a cento e vinte (96-120) horas. A frequiência de recorrências varia de indivíduo para indivíduo.

Outras lesões cutâneas pelo HSV-1 manifestam-se, como eczema herpético, em pacientes com dermatite atópica. Estas podem ser localizadas, lembrando herpes zoster, ou disseminadas. Outra forma de infecção cutânea é a paroníquia herpética. A incidência desta afecção é de 2,4 casos por 100,000 pessoas, por ano, e pode ser causada pelo HSV-1 ou HSV-2. Infecções herpéticas mais raras são as infecções cutâneas disseminadas, que têm sido descritas entre lutadores (herpes gladitorium).

Herpes genital primário manifesta-se como máculas e pápulas, seguidas por vesículas, pústulas, e úlceras ${ }^{(5,6)}$. As lesões persistem por aproximadamente três (03) semanas e a excreção viral pode acontecer ao longo de todo este período. Em homens, complicações sistêmicas são relativamente incomuns, exceto pela meningite asséptica que, raramente, pode complicar o quadro. Infecções primárias, em mulheres, são mais graves e mais frequientemente associadas com complicações. Parestesias e disestesias, envolvendo as extremidades inferiores e o períneo, podem complicar a infecção herpética genital. Infecções primárias são, normalmente, associadas a febre, disúria, adenopatia inguinal localizada e mal-estar, em homens e mulheres.

Manifestações sistêmicas são comuns em ambos os sexos, em aproximadamente $70 \%$ dos pacientes. Em mulheres com infecção primária, lesões aparecem na vulva e são normalmente bilaterais; a cérvix uterina é, invariavelmente, envolvida. A frequiência de infecção cervical primária, na ausência de infecção vulvar, é desconhecida. As lesões, normalmente, são extremamente dolorosas, associadas com adenopatia 
inguinal e disúria, podendo envolver a vulva, períneo, nádegas, cérvix uterina e vagina. Retenção urinária ocorre em 10-15\% das pacientes do sexo feminino, e aproximadamente $25 \%$ delas desenvolverão meningite asséptica. Em pacientes do sexo masculino, infecções genitais primárias pelo HSV são freqüentemente associadas com lesões vesiculares, localizadas sobre uma base eritematosa, normalmente restritas à glande ou ao corpo do pênis. Outras lesões extragenitais ocorrem em coxas, nádegas, e períneo.

Outras complicações que podem aparecer após a infecção herpética primária da região genital, independentes do sexo do indivíduo, incluem radiculomielite sacral, neuralgia e meningoencefalite. Infecções primárias da região perianal pelo HSV-2 e proctite são comuns em homossexuais masculinos. A infecção genital, em pacientes apresentando infecções de outros sítios, é, normalmente, menos grave e costuma curar-se mais depressa. A duração da infecção, normalmente, é de duas (02) semanas. O número de lesões, a intensidade da dor e a probabilidade de complicações são reduzidos nestes pacientes. A presença de anticorpos para HSV-1 torna a doença causada pelo HSV-2 menos grave.

Com a infecção herpética genital recorrente, um pequeno número de vesículas (três a cinco) costuma aparecer no corpo do pênis de indivíduos do sexo masculino ou apresentar-se simplesmente como irritação vulvar em indivíduos do sexo feminino. A duração da doença compara-se com a da infecção labial recorrente, isto é, oito a dez (08-10) dias. Complicações neurológicas ou sistêmicas são incomuns com a doença recorrente, porém, parestesias podem ser um achado comum. $\mathrm{O}$ vírus é excretado em média por dois a cinco (02-05) dias. Infecções genitais recorrentes, de origem herpética, em homens e mulheres, são caracterizadas por um período prodrômico, caracterizado, primariamente, por irritação local. A freqüência de recorrências varia entre os indivíduos infectados. A gravidade da infecção primária parece estar relacionada com a frequiência de recorrências, isto é, quanto mais grave a infecção primária, mais prováveis e freqüentes serão as recorrências. Pacientes com recorrências sintomáticas ou assintomáticas podem transmitir a infecção aos seus parceiros sexuais $^{(7)}$. É possível demonstrar, por PCR, uma alta freqüência de HSV DNA em secreções genitais entre as recorrências clinicamente aparentes ${ }^{(8)}$.

A infecção genital pelo HSV pode, raramente, se disseminar durante a gravidez e envolver várias visceras, resultando em hepatite necrotizante, as- sociada ou não com plaquetopenia, coagulação intravascular disseminada e encefalite. A mortalidade associada ao HSV, entre mulheres grávidas, pode ser $>50 \%$, assim como a mortalidade fetal. Portanto, infecção herpética durante a gestação eleva o risco de complicações para o feto e para a mãe.

\section{Infecções do SNC}

A encefalite é a mais grave das infecções causadas pelo HSV. O HSV-1 é considerado como o causador mais comum de encefalite esporádica e está associado a uma alta letalidade. As manifestações clínicas da encefalite pelo HSV em crianças mais velhas e adultos estão relacionadas com as áreas afetadas do cérebro. Estas manifestações incluem, principalmente, uma encefalite focal, que está associada com febre, alterações da consciência ou do comportamento e distúrbios neurológicos localizados. Muito freqüentemente, os sintomas e sinais clínicos indicam doença restrita ao lobo temporal. Nenhum sinal é patognomônico da encefalite pelo HSV, porém, pacientes apresentando nível de consciência que vai, progressivamente, deteriorando-se em associação com febre, parâmetros liquóricos alterados e achados neurológicos focais, na ausência de outras causas, são altamente sugestivos desta doença. A mortalidade entre os pacientes sem tratamento excede $70 \%$ e somente $2.5 \%$ de pacientes que sobrevivem recuperam função neurológica normal ${ }^{(9)}$.

Procedimentos diagnósticos, regularmente usados na avaliação de pacientes com doenças neurológicas, são empregados no diagnóstico da encefalite pelo HSV e incluem exame liquórico, eletroencefalografia, e métodos de imagem, como tomografia computadorizada ou ressonância magnética. As anormalidades liquóricas, características da encefalite pelo HSV, incluem níveis elevados de leucócitos (normalmente, mononucleares), hemácias e proteína. O eletroencefalograma mostra a presença de ondas lentas e amplas, restritas ao lóbulo temporal. Os métodos de imagem, confirmando os achados eletroencefalográficos, geralmente, localizam a doença ao lobo temporal. No início da doença, estes exames mostrarão apenas a evidência de edema ou um resultado completamente negativo. Tardiamente, este achado é seguido por evidências de hemorragia e desvio da linha média nas estruturas corticais.

Além do cérebro, os HSV podem envolver, virtualmente, todas as áreas anatômicas do sistema nervoso e podem causar manifestações, como meningites, mielites e radiculites. 


\section{Doença Neonatal}

A incidência calculada de infecção neonatal pelo HSV é de, aproximadamente, um caso em dois mil a cinco mil (2.000-5.000) partos por ano. Alguns fatores influenciam a infecção da mãe para o feto, entre eles, 1) a taxa de transmissão, que é de 30-50\%, quando da infecção materna primária ou inicial, reduz-se para com $\leq 3 \%$ nas infecções recorrentes ${ }^{(10)} ; 2$ ) a presença de anticorpos maternos contra os HSV, antes do parto, influencia tanto a gravidade da infecção como a probabilidade de transmissão; e 3) a ruptura prolongada das membranas ( $\geq 6$ horas) aumenta o risco de infecção ascendente.

O recém-nascido pode adquirir a infecção por diferentes vias, mas a mãe é a fonte mais comum de infecção, em todos os casos. A infecção intra-útero é rara e requer critérios diagnósticos bem definidos (isto é, identificação dos neonatos infectados dentro das primeiras quarenta e oito (48) horas de vida, por meio da cultura viral). A infecção fetal "intrapartum" acontece através do contato do feto com secreções genitais maternas infectadas. É provável que $\sim 75-80 \%$ dos neonatos adquiram a infecção pelo HSV por esta via. Uma outra via de transmissão dos HSV é a pós-natal. Nesta forma rara de infecção, parentes e profissionais da saúde, envolvidos com o cuidado do recémnascido, podem servir de reservatórios para a infecção pelo HSV nos recém-nascidos. A infecção pelo HSV em neonatos é, quase que invariavelmente, sintomática e freqüentemente fatal. Estes recém-nascidos com infecção congênita devem ser identificados dentro de quarenta e oito (48) horas do nascimento. A doença congênita é caracterizada pela tríade de vesículas de pele ou escarificações, acometimento ocular, e microcefalia ou hidrocefalia. Doenças pelos HSV podem ocorrer em neonatos infectados durante ou depois do nascimento, acometendo a pele, olhos e boca; encefalite com ou sem envolvimento cutâneo; e infecção disseminada, que acomete aproximadamente $25 \%$ dos neonatos com doença herpética neonatal e está associada com pior prognóstico ${ }^{(11)}$.

\section{Ceratoconjuntivite herpética}

Infecções virais do olho, ocorrendo após o período neonatal, normalmente são causadas pelo HSV-1. A ceratoconjuntivite pelo HSV pode ser unilateral ou bilateral e, geralmente, está associada a adenopatia pré-auricular. A ceratoconjuntivite herpética também está associada com fotofobia e lacrimejamento, edema palpebral, e quemose, bem como com o achado patognomônico das lesões dendríticas. Pa- cientes com doença avançada podem apresentar úlceras geográficas da córnea. A frequiência de recorrências compara-se àquela descrita para o herpes labial. A maioria são recorrências unilaterais mas, em uma porcentagem pequena dos casos, envolvem ambos os olhos.

\section{Infecções do hospedeiro imunocomprometido}

Pacientes imunocomprometidos, particularmente receptores de órgãos transplantados, apresentam um risco aumentado para infecções graves pelo HSV. Estes pacientes podem contrair doença progressiva, envolvendo o trato respiratório, esôfago ou o trato gastrintestinal. A natureza grave da doença, nestes pacientes, parece estar relacionada diretamente com a intensidade e a duração da terapia imunossupressiva. A esofagite acontece, comumente, em pacientes imunocomprometidos e pode ser causada pelo HSV, citomegalovírus, ou Candida Albicans. Infecções por cepas de HSV resistentes ao aciclovir podem ser detectadas em pacientes imunocomprometidos, podendo ser progressivas, particularmente naqueles com a síndrome da imunodeficiência adquirida.

\section{TRATAMENTO}

O aciclovir [9-(2-hidroxiyetoximetil) guanina], um análogo acíclico e sintético dos nucleosídeos purínicos tornou-se o padrão da terapia para infecções pelo $\mathrm{HSV}^{(3)}$. O valaciclovir, um precursor que se converte em aciclovir, e o famciclovir (converte-se em penciclovir) foram, recentemente, autorizados para o tratamento das infecções herpéticas, e possuem maior biodisponibilidade oral do que o aciclovir e o penciclovir.

\section{Herpes genital}

A infecção genital primária pelo HSV pode ser tratada com aciclovir tópico, oral ou intravenoso. Embora a aplicação tópica de aciclovir reduza a duração da excreção viral e abrevie o tempo necessário para que as lesões adquiram crostas, este tratamento é menos efetivo do que o tratamento por via oral ou intravenosa. $\mathrm{O}$ aciclovir intravenoso é o tratamento mais efetivo para o primeiro episódio de herpes genital e resulta em redução significante na duração média da excreção viral, da dor e do tempo para a cura completa. Desde que a terapia com aciclovir intravenoso, normalmente, requer hospitalização do paciente, este deve ser reservado para aqueles casos com doença local severa ou com complicações sistêmicas. A tera- 
pia oral (200mg 5X/dia) é quase tão efetiva quanto a terapia intravenosa nos episódios iniciais de herpes genital e vem sendo considerada o tratamento padrão (Tabela I). Valaciclovir e famciclovir oferecem graus semelhantes de sucesso terapêutico ao do aciclovir. Infelizmente, nem o tratamento intravenoso nem o oral com aciclovir, para infecção aguda pelo HSV, reduzem a freqüência das recorrências.

$\mathrm{O}$ herpes genital recorrente é menos severo e cura-se mais rapidamente do que a infecção primária. Assim, há menos tempo para introduzir quimioterapia antiviral adequada. A terapia com aciclovir oral encurta ambos, a duração da excreção viral e a duração de tempo para cura (seis (06) vs sete (07) dias), quando se inicia a terapêutica precocemente (dentro de vinte e quatro (24) horas do início do quadro), mas a duração dos sintomas e o intervalo entre as recorrências não é afetado. Neste aspecto, o valaciclovir e o famciclovir não acrescentaram nenhum benefício à terapêutica contra os HSV.

A administração oral de aciclovir, valaciclovir, ou famciclovir, a longo prazo, suprime, de maneira eficaz, o herpes genital em pacientes que têm recorrências freqüentes. A administração diária de aciclovir reduz a frequiência de recorrências em aproximadamente $80 \%$ e, $25-30 \%$ dos pacientes não terão nenhuma recorrência adicional, enquanto estiverem tomando aciclovir. Muitas vezes, é necessário titular a dose de aciclovir (400 mg 2X/dia ou $200 \mathrm{mg} 2-5 \mathrm{X} /$ dia) para deteminar a dose mais efetiva e econômica. Tratamento deve ser interrompido após doze (12) meses para reavaliar a necessidade de supressão contínua. $\mathrm{O}$ aparecimento de cepas de HSV resistentes ao aciclovir parece ser infreqüente em indivíduos normais, sem alteração do sistema imune. É importante assinalar que a excreção do vírus continua apesar da supressão clínica efetiva com aciclovir. Assim, a possibilidade de transmissão de pessoa para pessoa ainda persiste.

\section{Herpes Labial}

A terapia tópica com famciclovir/penciclovir acelera a cura clínica em $\sim 1$ dia. O aciclovir $(200 \mathrm{mg}$ $5 \mathrm{X} /$ dia durante cinco (05) dias) reduz a duração de tempo de cura até a perda das crostas por $\sim 1$ dia (sete (07) vs oito (08) dias), mas não altera a duração da dor ou o tempo para a cura completa. A administração oral do aciclovir pode alterar a gravidade de reativação das infecções labiais induzidas pelo sol. Uma terapia profilática de curto prazo com aciclovir pode beneficiar indivíduos com herpes labial recorrente, antecipando participação em atividades de alto risco (por exemplo, intensa exposição à luz solar). A administração intermitente deve ser evitada, pois o aciclovir não altera a freqüência de recorrências subseqüentes. Não há nenhuma evidência de que o tratamento, a longo prazo, com quaisquer destas drogas, previna as recorrências das lesões labiais de origem herpética.

\section{Infecções Mucocutâneas em Pacientes Imuno- comprometidos}

A terapia com aciclovir intravenoso para infecções herpéticas, em imunocomprometidos, é extremamente benéfica para estes pacientes. Indivíduos imunocomprometidos, usando aciclovir, excretam o vírus por menor período e as lesões curam-se mais rapidamente do que em pacientes tomando placebo. A terapia oral com aciclovir é bastante efetiva nestes pacientes. Profilaxia com aciclovir contra infecções herpéticas, também, tem valor clínico nos imunocomprometidos, particularmente naqueles em regime de quimioterapia ou receptores de transplantes. A administração intravenosa ou oral de aciclovir reduz a incidência de infecção sintomática pelo HSV de aproximadamente $70 \%$ a 5-20\%. Dados semelhantes existem para o famciclovir e o valaciclovir. A terapêutica seqüencial, com aciclovir intravenoso, seguida de aciclovir oral por três a seis (03-06) meses pode, virtualmente, eliminar, infecções sintomáticas pelo HSV, em receptores de órgãos. Doses orais, variando de 200 $\mathrm{mg} 3 \mathrm{X} /$ dia a $800 \mathrm{mg} 2 \mathrm{X} /$ dia, têm sido usadas com sucesso. Cepas de HSV, resistentes ao aciclovir, têm 
sido isoladas, mais freqüentemente, após a administração terapêutica de aciclovir do que durante a profilaxia, entre os receptores de transplantes de medula óssea e pacientes com aids. Cepas de HSV resistentes ao aciclovir, normalmente, também o são para famciclovir/penciclovir ${ }^{(12)}$.

\section{Encefalite pelo HSV}

A encefalite pelo HSV está associada a uma morbidade e a uma mortalidade significativa, apesar do uso de terapia antiviral. A administração de aciclovir, na dose de $10 \mathrm{mg} / \mathrm{kg}$ a cada 8 horas por 10-14 dias, reduz a mortalidade, após três (03) meses, para $19 \%$, em comparação com $~ 50 \%$ entre pacientes tratados com vidarabine ${ }^{(13)}$. Além disso, $38 \%$ dos pacientes tratados com aciclovir recuperam função neurológica normal. O prognóstico é ruím para pacientes com Glasgow menor que seis (06), para aqueles maiores de trinta anos e para aqueles que tiveram encefalite por período superior a quatro (04) dias ${ }^{(13)}$.

\section{Infecções Neonatais}

Em um estudo comparativo ${ }^{(14)}$, o aciclovir foi tão efetivo quanto (mas não superior) à vidarabina, no tratamento de neonatos com infecções pelo HSV. Nenhum neonato, com doença localizada à pele, olhos ou boca, morreu, enquanto que $18 \%$ dos neonatos, com infecção do SNC e 55\% dos com infecção disseminada, morreram. Os parâmetros relacionados ao desenvolvimento destas crianças também foram similares entre os neonatos com infecções herpéticas da pele, olho e boca, bem como naqueles que sobreviveram à encefalite e à infecção disseminada ${ }^{(15)}$. Assim, diferente dos resultados da terapia em pacientes mais velhos, com encefalite pelo herpes símplex, não houve diferença significante em morbidade ou mortalidade entre neonatos tratados com aciclovir ou vidarabina. O clareamento da infecção viral foi mais lento em neonatos que receberam aciclovir do que em adultos imunocomprometidos, demonstrando a necessidade da existência de mecanismos de defesa adequados no hospedeiro.

A segurança e a facilidade de administração do aciclovir caracterizam-no como o tratamento de escolha para as infecções herpéticas neonatais. A dose intravenosa recomendada é $10 \mathrm{mg} / \mathrm{kg} 8 / 8$ horas $^{(16)}$.

\section{Outras Infecções pelo HSV}

Relatos de caso descrevem, com sucesso, o uso do aciclovir no tratamento de outras infecções herpé- ticas, como hepatites, infecções pulmonares, esofagite, proctite eczema herpético e panaríceo herpético. A terapia tópica com aciclovir para infecções herpéticas oculares é efetiva mas, provavelmente, não superior à com trifluridine ${ }^{(17)}$.

\section{Resistência Viral}

Como acontece com todos os antimicrobianos, algumas cepas de HSV podem desenvolver resistência ao aciclovir. A resistência ao aciclovir acontece através de mutações no gene viral que codifica a enzima timidina-quinase (TK), gerando mutantes deficientes em TK, ou pela seleção de mutantes que possuem uma TK incapaz de fosforilar o aciclovir. Cepas de HSV, resistentes ao aciclovir, isoladas de amostras clínicas são quase que uniformemente deficientes em TK, embora cepas com DNA polimerase alterada tenham sido recuperadas de pacientes infectados pelo HSV. Embora os HSV resistentes ao aciclovir sejam suscetíveis à vidarabina e ao foscamet in vitro, só o foscamet mostrou-se efetivo no tratamento das infecções devidas a HSV resistente ao aciclovir. Estas cepas resistentes foram identificadas como causadoras de pneumonia, encefalite, esofagite e infecções mucocutânea, em pacientes imunocomprometidos ${ }^{(18 / 21)}$.

\section{Toxicidade}

O tratamento com aciclovir, valaciclovir e famciclovir está associado a alguns efeitos adversos. Insuficiência renal tem sido relatada, principalmente, em pacientes recebendo altas doses de aciclovir através de infusão intravenosa rápida, mas esta parece ser relativamente incomum e é reversível. O risco de nefrotoxicidade pode ser minimizado, administrando-se o aciclovir através de infusão lenta e mantendo o paciente adequadamente hidratado. Terapia com aciclovir oral, até mesmo com doses de $800 \mathrm{mg}$, cinco vezes por dia, não foi associada com doença renal. Alguns relatos associaram a administração intravenosa de aciclovir com perturbações do SNC, incluindo agitação, alucinações, desorientação, tremores e mioclonias ${ }^{(22)}$.

Análises da exposição pré-natal ao aciclovir não mostraram nenhum aumento no risco para mães ou para os fetos mas o número total de gestações monitorizadas ainda é muito pequeno para descobrir qualquer evento de baixa-freqüência ${ }^{(23)}$. Desde que o aciclovir cruza a placenta e concentra-se no líquido amniótico, existe preocupação sobre a potencial nefrotoxicidade fetal, embora nenhum evento deste tipo tenha sido observado. 
FONSECA BAL. Clinical manifestations and treatment of infections caused by herpes simplex 1 and 2 viruses. Medicina, Ribeirão Preto, 32: 147-153, apr./june 1999.

ABSTRACT: Herpes simplex viruses are known by mankind since the antiquity. These viruses are responsible for a number of diseases ranging from cutaneous lesions to severe cases of encephalitis. Nowadays, a specific antiviral, acyclovir, has been available for treatment of herpes simplex virus infections. This review discusses the use of acyclovir according to the clinical manifestations of herpes virus infections.

UNITERMS: Herpesvirus 1, Human. Herpesvirus 2, Human. Acyclovir.

\section{REFERÊNCIAS BIBLIOGRÁFICAS}

1 - WILDY P. Herpes: history and classification. In: KAPLAN AS, ed. The herpesviruses. Academic Press, New York, p. $1-25,1973$.

2 - ROIZMAN B \& SEARS AE. Herpes simplex viruses and their replication. In: FIELDS BN; KNIPE DM \& HOWLEY PM, eds. Fields virology. Lippincott-Raven, Philadelphia; p. 2231-2295,1996.

3 - WHITLEY RJ \& GNANN JW. The epidemiology and clinical manifestations of herpes simplex virus infections. In: ROIZMAN B; WHITLEY RJ \& LOPEZ C., eds. The human herpes viruses. Raven, New York; p. 69-105,1993.

4 - SPRUANCE ST; OVERALL Jr JC \& KEM ER. The natural history of recurrent herpes simplex labialis-implications for antiviral therapy. N Engl J Med 297: 69-75, 1977.

5 - COREY L et al. Genital herpes simplex virus infections: clinical manifestations, course and complications. Ann Intern Med 98: 958-972, 1983.

6 - COREY L. The diagnosis and treatment of genital herpes. JAMA 248:1041-1049, 1982.

7 - MERTZ GJ et al. Risk factors for the sexual transmission of genital herpes. Ann Intern Med 13: 197-202, 1992.

8 - WALD A et al. Virologic characteristics of subclinical and symptomatic genital herpes infections. N Engl J Med 333: 770-775, 1995.

9 - WARD PL \& ROIZMAN B. Herpes simplex genes: the blueprint of a successful pathogen. Trends Genet 10: 267-274, 1994.

10 - BROWN ZA et al. Neonatal herpes simplex virus infection in relation to asymptomatic maternal infection at the time of labor. N Engl J Med 324:1247-1252, 1991.

11 - WHITLEY RJ et al. Changing presentation of herpes simplex virus infection in neonates. J Infect Dis 158: 109-113, 1988.

12 - ERLICH KS et al. Acyclovir-resistant herpes simplex virus infections in patients with the acquired immunodeficiency syndrome. N Engl J Med 320: 293-296, 1989.

13 - WHITLEY RJ et al. Vidarabine versus acyclovir therapy in herpes simplex encephalitis. N Engl J Med 314:144-149; 1986.
14 - WHITLEY RJ et al. A controlled trial comparing vidarabine with acyclovir in neonatal herpes simplex virus infection diseases. Infectious Diseases Collaborative Antiviral Study Group. N Engl J Med 324: 444-449, 1991.

15 - WHITLEY RJ et al. Predictors of morbidity and mortality in neonates with herpes simplex virus infections. N Engl J Med 324: 450-454, 1991.

16 - GUTMAN LT; WILFERT CM \& EPPES S. Herpes simplex virus encephalitis in children: analysis of cerebrospinal fluid and progressive neurodevelopmental deterioration. J Infect Dis 154: 415-421, 1986.

17 - HOVDING G. A comparison between acyclovir and trifluorothymidine ophthalmic ointment in the treatment of epithelial dendritic keratitis. A double blind, randomized parallel group trial. Acta Ophthalmol (Copenh) 67: 51-54, 1989.

18 - SACKS SL et al. Progressive esophagitis from acyclovirresistant herpes simplex. Clinical roles for DNA polymerase mutants and viral heterogeneity? Ann Intern Med 111: 893-899, 1989.

19 - SAFRIN S et al. A controlled trial comparing foscarnet with vidarabine for acyclovir-resistant mucocutaneous herpes simplex in the acquired immunodeficiency syndrome. The AIDS Clinical Trials Group. N Engl J Med 325: 551-555, 1991.

20 - GATELEY A et al. Herpes simplex virus type 2 meningoencephalitis resistant to acyclovir in a patient with AIDS. J Infect Dis 161: 711-715, 1990.

21 - ENGLUND JA et al. Herpes simplex virus resistant to acyclovir. A study in a tertiary care center. Ann Intern Med 112: 416-422, 1990.

22 - COHEN SM et al. Severe but reversible neurotoxicity from acyclovir. Ann Intern Med 100: 920; 1984.

23 - ANDREWS EB et al. Acyclovir in Pregnancy Registry: an observational epidemiologic approach. Am J Med 85: 12-19, 1988. Suppl 2 A.

Recebido para publicação em 05/05/99

Aprovado para publicação em 02/06/99 